\title{
Synthesis of coral-like silver chloride-polypyrrole nanocomposites derived from silver nanoparticles and the study of their structural, thermal, optical, and electrical properties
}

\author{
Farah Kanwal ${ }^{1}$, Aisha Batool ${ }^{2}$, *, Muniba Aslam ${ }^{1}$, Fatima Aziz ${ }^{1}$, Shahzad Ahmad ${ }^{3}$ \\ ${ }^{1}$ Deptartment of Chemistry, University of the Punjab, \\ Lahore, Pakistan \\ ${ }^{2}$ School of Physical Sciences, University of the Punjab, \\ Lahore, Pakistan \\ ${ }^{3}$ School of Economics and Management, Beijing Forestry University, \\ Beijing-100083, China \\ *Corresponding author: dr.batool.aisha@gmail.com
}

\begin{abstract}
In this research, we developed a facile method for the synthesis of silver chloride: polypyrrole ( $\mathrm{AgCl}$ : PPy) nanocomposites with enhanced structural, thermal, optical, and conducting properties. Polypyrrole monomer was in-situ doped with varying weight percentages of assynthesized Ag nanoparticles by following simple chemical oxidation polymerization technique to form $\mathrm{AgCl}$ : PPy nanocomposites. The $\mathrm{AgCl}$ nanostructures with tree-like coral morphology are distributed uniformly into the PPy matrix without any segregation. The Fourier transform infrared spectroscopy results reveal the successful incorporation of $\mathrm{AgCl}$ in the organic structure of PPy. X-ray diffraction analysis shows the formation of $\mathrm{AgCl}$ nanostructures in the PPy matrix during the chemical polymerization process that increases the crystallinity of amorphous PPy. The TGA analysis demonstrates the improved thermal stability of PPy nanocomposites due to the development of physiochemical interactions between the $\mathrm{AgCl}$ and $\mathrm{PPy}$ moities, this is also inferred from Fourier transform infrared results. It is noted that the electrical conductivity of $\mathrm{AgCl}$ : PPy nanocomposites is significantly controlled by the weight percentage of dispersed Ag nanoparticles in the polymerization assembly. The highest conductivity $\left(1335 \mathrm{~S} \mathrm{~cm}^{-1}\right)$ of PPy nanocomposite is attributed to the decrease in particle size, shortening of the PPy chain length, and lower bandgap energy presented at the critical weight percentage of Ag nanoparticles.
\end{abstract}

Keywords: Bandgap; crystallinity; morphology; polypyrrole nanocomposites; silver chloride.

\section{Introduction}

Conducting polymers has gained immense interest owing to their quasimetallic properties in either $\mathrm{p}$-doped (oxidized) or n-doped (reduced) state. In this class of polymers, the conductivity is attributed to the $\mathrm{sp}^{2}$-hybridized carbon atoms in the conjugated backbone of polymer (Kurt et al., 2016; Pang et al., 2015). The pz -orbital of carbon atoms lay a pair of $\pi$-bonds HOMO and LUMO, which help the charge carriers to move in the polymer chain (Yi et al., 2016; Bolto et al., 1963). The conducting polymers are oxidized by electron donors or reduced by electron acceptors for the generation of charge carriers in the process called "doping" (Yi et al., 2016). Thus, the electrical conductivity of conducting polymers is designated to the generation of solitons, polarons, or bipolarons during doping or polymerization of its monomer (Ravichandran et al., 2010; Pitachi et al., 2014; Younas et al., 2015). The study of conducting polymers has led to a wide range of energy applications. It has a great impact in the field of organic electronics such as organic photovoltaics (OPVs), organic light-emitting diodes (OLEDs), and electrochromic devices (Kim et al., 2002; 
Stenger-Smith et al.,1998). They are also applicable in the biomedical field in the development of drug delivery systems, tissue engineering, and electrically active biosensors (Ravichandran et al., 2010). One of their major application is the production of rechargeable batteries for portable devices and vehicles (Levi et al., 2002).

Among the conducting polymers, polypyrrole (PPy) and its derivatives up-holds a major interest due to its decisive stability in an oxidized state and its redox properties (Vernitsakaya et al., 1997). Moreover, the ease in accessibility and the polarizability by chemical and electrochemical oxidation of pyrrole monomer is of specific importance (Ruggeri et al.,1997). The first conductive PPy was synthesized by heating tetraiodopyrrole at $120^{\circ} \mathrm{C}$ having characteristic conductivity of 0.005-0.09 $\Omega^{-1} \mathrm{~cm}^{-1}$ (Bolto et al., 1963). Later on much conductive PPy was synthesized using electrochemical oxidation, as reported by Diaz, exhibiting the conductivity of $10-100 \Omega^{-1} \mathrm{~cm}^{-1}$ (Khanazawa et al., 1979). The later developed PPy films by electrochemical polymerization were thin and better adhered to the surface in a repeatable manner. The conductivity of PPy is controlled by the type of solvent used and the charge carriers that are generated by doping (Kanwal et al., 2011). Despite its good mechanical properties, PPy suffers from poor conductivity and a lack of thermal stability that restricted its uses (Yusoff et al., 2019). The conductivity of PPy can be improved by composite formation. PPy has been reported for the synthesis of composite with inorganic particles i.e. Ag (Wang et al., 2010), $\mathrm{AgCl}$ (G et al., 2011), and $\mathrm{Au}$ (Du et al., 2015). The AgCl: PPy is usually reported to be synthesized by the chemical oxidation of $\mathrm{AgNO} 3$ using various oxidants preferably ammonium persulphate (APS) (Liu et al., 2015) and ferric chloride (FeCl3) (Yang et al., 2010). The Ag: PPy nanocomposites were used as a photocatalyst (Gu et al., 2011), the sensor for chloride estimation (Guo et al., 2009), and antibacterial activity (Liu et al., 2015). The fairly homogenous distribution of metal-based nanoparticles in the PPy matrix is always a challenge as there is a lot of chances for the aggregation and loss of metal content (Yang et al., 2010).

In this work, we adopted a facile and simple in-situ chemical oxidation route for the synthesis of $\mathrm{AgCl}$ : PPy nanocomposites with non-segregated morphology by chemical oxidation of pyrrole and $\mathrm{Ag}$ nanoparticles (NPs) (Novak, 1992). The effect of varying weight percentages of Ag NPs on the physical properties of synthesized $\quad \mathrm{AgCl}$ PPy nanocomposites are studied. The results demonstrate that our method of structural modification also has successfully improved the structural, thermal, optical, and conducting properties of $\mathrm{AgCl}$ : PPy nanocomposites and hence enhanced the application prospect domains of this conducting polymer.

\section{Experimental section}

Iron chloride (III) hexahydrate $\left(\mathrm{FeCl}_{3} \cdot 6 \mathrm{H}_{2} \mathrm{O}\right)$ from Merck, silver nitrate $\left(\mathrm{AgNO}_{3}\right)(\mathrm{AR}$ grade) from Sigma-Aldrich, acetone (AR > 99.7\%), and pyrrole from Fluka were used in this research work. Pyrrole was distilled before use and was stored at $0^{\circ} \mathrm{C}$ in dark to avoid its photopolymerization. All solutions and products were prepared and washed in doubly distilled water.

2.1 Synthesis of silver nanoparticles (Ag NPs)

Citrus limon leaves extract was used as a reducing agent for the synthesis of Ag NPs. For its synthesis, in the first step, 20 grams of fresh lemon leaves were obtained from the Botanical garden of the University of the Punjab, Lahore, Pakistan. They were washed thoroughly with water and then dried. These citrus lemon leaves were finely chopped down and boiled in $100 \mathrm{ml}$ water for 20 minutes. The extract obtained was filtered by using whattman filter paper 42. The obtained extract product was cooled down and then was 
used for the synthesis of Ag NPs. Then, in the second step, $5 \mathrm{ml}$ of prepared extract was added in $45 \mathrm{ml}$ of $100 \mathrm{mM} \mathrm{\textrm {AgNO } _ { 3 }}$ solution. The solution was covered with aluminum foil and was kept in dark at room temperature. The color change was observed from milky to brown after 2-3 hours that indicated the formation of Ag NPs. This solution was then centrifuged thrice at the speed of $4000 \mathrm{rpm}$, each for 10 minutes, and then finally washed with water. The product was dried at $50^{\circ} \mathrm{C}$ overnight.

\subsection{Synthesis of PPy nanocomposites (AgCl:} PPy)

PPy was synthesized by adopting the typical chemical oxidation method of polymerization. For this, a $30 \mathrm{mM}$ aqueous solution of $\mathrm{FeCl}_{3} \cdot 6 \mathrm{H}_{2} \mathrm{O}$ was used as an oxidizing agent, prepared in distilled water. This chemical solution was purged with nitrogen gas to remove the excess oxygen from the reactor assembly. $6.7 \mathrm{ml}$ of distilled pyrrole was added drop-wise in the reaction assembly flask at $0^{\circ} \mathrm{C}$ under constant stirring. After the addition of pyrrole monomer in the oxidant solution, the chemical mixture was kept on stirring for $1 \mathrm{~h}$ hour. The polymerization was indicated by the change of solution color from orange-yellow to grayish black.

For the synthesis of $\mathrm{AgCl}$ : PPy nanocomposites, in the first step, varying weight percentages of $\operatorname{Ag}$ NPs $(67,134$, and $201 \mathrm{mg}$ ) were added in $100 \mathrm{ml}$ water for $3 \%$, $6 \%$, and $9 \% \mathrm{AgCl}$ : PPy. This mixture was sonicated for 20 minutes for homogeneous dispersion of Ag NPs. Next, 8.3 grams of $\mathrm{FeCl}_{3} \cdot 6 \mathrm{H}_{2} \mathrm{O}$ was added to the NPs solution and then $6.7 \mathrm{ml}$ of pyrrole (Py) monomer was added dropwise under constant stirring for one hour at $0^{\circ} \mathrm{C}$. Ag NPs and pyrrole both were oxidized by $\mathrm{FeCl}_{3}$ during chemical oxidation polymerization. The precipitation reaction between $\mathrm{Ag}^{+}$and $\mathrm{Cl}^{-}$at $0^{\circ} \mathrm{C}$ resulting in precipitation and conversion of $\mathrm{Ag}$ NPs to $\mathrm{AgCl}$ nanostructured branches embedded in PPy. The color of $\mathrm{AgCl}$ : PPy composites was dark black due to the formation of $\mathrm{AgCl}$ precipitates in the PPy composite. The resulting $\mathrm{AgCl}$ : $\mathrm{PPy}$ nanocomposites were vacuum filtered and washed with acetone followed by distilled water three times to remove any unreacted organic species and were dried at $60^{\circ} \mathrm{C}$.

In this reaction, the $\mathrm{FeCl}_{3}$ acts as an oxidizing agent and an initiator in the oxidative chemical polymerization process. The generated $\mathrm{Cl}^{-}$anions in the aqueous solution of $\mathrm{FeCl}_{3}$ help in the conversion of neutral Py monomer into $\mathrm{Py}^{+}$cations (Setka et al., 2017). These $\mathrm{Py}^{+}$cations serve in the polymerization process, forming the PPy backbone and giving the black-colored composite. While the excess $\mathrm{Cl}^{-}$anions react with $\mathrm{Ag}^{+}$to form $\mathrm{AgCl}$ nanostructures embedded in PPy.

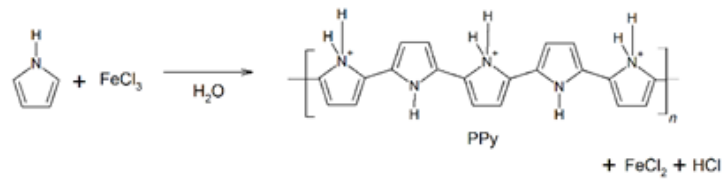

In the formation of composite, Ag NPs reacted with the generated free chloride anions to generate $\mathrm{AgCl}$.

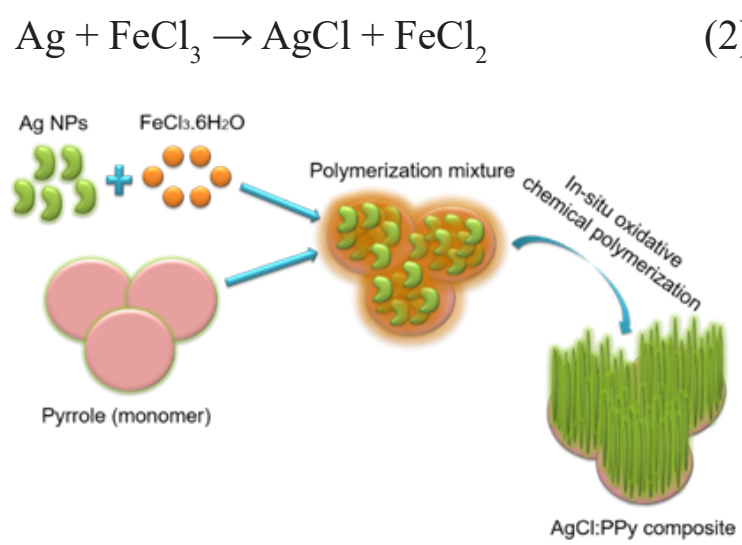

Scheme 1. Schematic illustration for the synthesis of $\mathrm{AgCl}$ : PPy nanocomposites

\subsection{Characterizations}

Perkin Elmer RXI FT-IR Spectrophotometer was operated at room temperature within the range of $400 \mathrm{~cm}^{-1}$ to $4000 \mathrm{~cm}^{-1}$ for structural analysis. Synthesized products were dispersed 
in powdered potassium bromide $(\mathrm{KBr})$ and pressed into pellets. The SEM analysis was done by using S4800 to get microstructured information about the respective samples. It helps to find out the surface topography and symmetry of particles in the prepared sample. The optical property of synthesized polymer composite was analyzed by the UV absorption spectrum recorded in the range of $200 \mathrm{~nm}$ to $800 \mathrm{~nm}$. X-ray diffraction Analysis of polymer composite was carried out by PANanalytical X'pert Pro DY-3805 using $\mathrm{CuK} \alpha(\lambda=1.54 \AA)$ radiations in the $2 \theta$ within the range of $10^{\circ}-80^{\circ}$. The DC conductivity of polymer composite was measured by finding resistance from the typical four-probe method using Keithley 2400. For this purpose pallets of PPy and $\mathrm{AgCl}$ : PPy nanocomposites were made using an apex hydraulic press under the applied pressure of 4000 to $5000 \mathrm{kPa}$ for 15 minutes. The dimensions of constructed pallets were measured by using a screw gauge for further calculations of conductivity. The conductivity is calculated using the equation:

$$
\sigma=\mathrm{L} / \mathrm{A} \cdot \mathrm{R}
$$

When, $\mathrm{R}$ is the calculated resistance of composites $\mathrm{L}$ and $\mathrm{A}$ are the length and area of prepared pallets, respectively and $\sigma$ is the conductivity calculated in $\mathrm{S} \mathrm{cm}^{-1}$. Thermogravimetric analysis (TGA) was done using TGA-701 Leco Company, S.A to measure the thermal properties of respective samples. The procedure was held under an air atmosphere from $20-800^{\circ} \mathrm{C}$ with a heating rate of $10^{\circ} \mathrm{C} / \mathrm{min}$ for bare polymer and nanocomposites as well.

\section{Results and discussion}

\subsection{X-ray diffraction (XRD) analysis}

The XRD patterns of bare PPy globules and their nanocomposites are shown in Figure 1. PPy exhibits a broad diffraction peak at about $2 \theta=24^{\circ}$. The light scattering from the inter-planner spacing of PPy leads to this broad peak formation (Novak, 1992) and shows its characteristic amorphous phase (Setka et al., 2017). Amorphous materials have lack long-range periodic order and scattering planes are not defined as well, therefore no sharp peaks can be observed in the case of polymers. It can be observed that PPy shows two very low-intensity diffraction peaks located at $24.1^{\circ}$ and $21.9^{\circ}$ that are not significantly spaced and considered as one broad peak. 0.9 while the other peak at $21.9^{\circ}$ is because of counter or inter-ions spacing between PPy groups (Partch et al., 1991). The calculated value of average chains separation (S) was found to be 0.237 $\mathrm{nm}$ from the relatively high-intensity peak of PPy at $2 \theta=24.1^{\circ}$ by using the relation: (Setka et al., 2017)

$$
\mathrm{S}=5 \lambda / 8 \sin \theta
$$

Where, $\mathrm{S}$ is the polymer chain separation, $\lambda$ is the X-ray wavelength and $\theta$ is the angle of diffraction at maximum intensity peak of the amorphous material. Figure $1 b$ shows the XRD pattern of as-synthesized Ag NPs with well-resolved Bragg's reflections at $2 \theta$ $=38.06^{\circ}, 44.5^{\circ}, 64.5^{\circ}$, and $77.1^{\circ}$ which is under the face-centered cubic crystal lattice planes of (111), (200), (220) and (311), respectively which are following the JCPDS file no. 03-0921 (Chougule et al., 2011). The diffraction peak of any other phase was not observed that confirmed the phase-purity of our as-synthesized Ag NPs. The calculated crystallite size of Ag NPs is found to be 9.92 $\mathrm{nm} \approx 10 \mathrm{~nm}$ as calculated from the (111) plane of Ag NPs located at $2 \theta=38.06^{\circ}$ by using the Debye-Scherrer formula:

$$
\mathrm{D}=\mathrm{k} \lambda / \mathrm{b} \operatorname{Cos} \theta
$$

Where, $\mathrm{k}=0.9$ is the shape factor, $\lambda$ is the $\mathrm{X}$-ray wavelength of $\mathrm{CuK} \alpha$ radiation (1.54 $\AA$ ), $\theta$ is the Bragg diffraction angle, and $b$ is the full width at half maximum (FWHM). The diffraction peaks at $2 \theta=27.86^{\circ}, 32.29^{\circ}$, $46.30^{\circ}, 54.90^{\circ}$, and $57.57^{\circ}$ can be assigned to (111), (200), (220), (311) and (222) crystal 
planes of cubic crystal system of $\mathrm{AgCl}$ (JCPDS no. 31-1238). It is noted that no peaks corresponding to elemental Ag were detected that reveal the phase transformation of $\mathrm{Ag}$ to $\mathrm{AgCl}$. The Scherrer equation when applied to the high-intensity characteristic (200) plane peak of $\mathrm{AgCl}$ at $2 \theta=32.24^{\circ}$ showed the particle size of $6 \% \mathrm{AgCl}$ : PPy decrease to $\sim 4 \mathrm{~nm}$ in nanocomposite (Table 1).

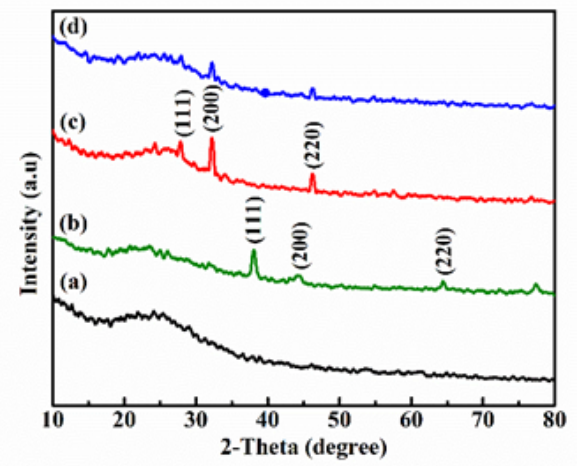

Fig. 1. XRD of (a) PPy, (b) Ag NPs, (c) 6\% Ag: PPy, and (d) 9\% Ag: PPy

Table 1. Particle sizes of Ag NPs, bare PPy, and $\mathrm{AgCl}$ : PPy nanocomposites

\begin{tabular}{lccc}
\hline Sample & $\mathbf{2 \theta}\left(^{\circ}\right)$ & FWHM $(\boldsymbol{\AA})$ & $\begin{array}{l}\text { Particle } \\
\text { size } \\
(\mathbf{n m})\end{array}$ \\
\hline Ag NPs & 38.06 & 0.941 & 9.92 \\
pure PPy & 24.20 & 14.76 & 0.58 \\
$6 \%$ AgCl:PPy & 32.24 & 0.596 & 4.00 \\
\hline
\end{tabular}

3.2 Fourier Transform Infrared (FT-IR) Spectroscopy

The FT-IR spectrum is recorded for bare $\mathrm{PPy}$ and $\mathrm{AgCl}$ : PPy nanocomposites from $4000 \mathrm{~cm}^{-1}$ to $400 \mathrm{~cm}^{-1}$. Figure $2 \mathrm{a}$ shows the FT-IR curve of pure PPy. The peak at $1560 \mathrm{~cm}^{-1}$ is attributed to the characteristic fundamental stretching vibration of $\mathrm{C}=\mathrm{C}$ in PPy ring (Ahmad et al., 2018). The peak at $1170 \mathrm{~cm}^{-1}$ corresponds to the inplane bending vibration of $=\mathrm{C}-\mathrm{H}$ of $\mathrm{PPy}$ ring (Chen et al., 2003). While the peaks at $1040 \mathrm{~cm}^{-1}$ and $965 \mathrm{~cm}^{-1}$ refer to the $-\mathrm{C}-\mathrm{H}$ in-plane bending and -C-C out-of-plane pyrrole ring deformations, respectively (Liu et al., 2015). The presence of these all characteristics peaks confirm the formation of PPy backbone. The FT-IR spectra of $\mathrm{AgCl}$ : PPy composites also reflect the similar characteristic peaks of bare PPy which indicate the dominating PPy phase in the synthesized composite products. It is noted that when compared to pure PPy, the FT-IR peaks of $3 \%, 6 \%$, and $9 \% \mathrm{AgCl}$ : PPy, the PPy characteristic peaks of $-\mathrm{C}=\mathrm{C}$ stretching and $=\mathrm{C}-\mathrm{H}$ in-plane bending shifted towards lower wavenumbers with the decrease in their absorption intensities in the range of $1545-1508 \mathrm{~cm}^{-1}$; and $1162-1125 \mathrm{~cm}^{-1}$, infers the shortening of PPy chain length that might be due to the interactions between PPy and $\mathrm{AgCl}$ in nanocomposites (Hayashi et al., 2017)

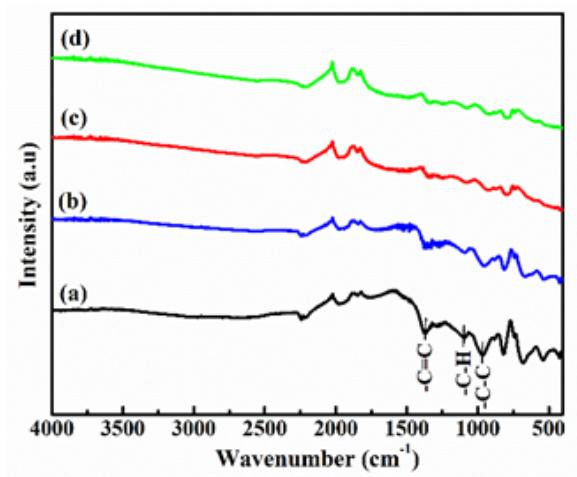

Fig. 2. FTIR spectra of (a) PPy, (b) 3\% Ag: PPy, (c) 6\% Ag: PPy, and (d) 9\% Ag: PPy

\subsection{Thermogravimetric analysis (TGA)}

The thermal behavior of as-synthesized $\mathrm{Ag} \quad \mathrm{NPs}$ and $\mathrm{AgCl}$ : PPy nanocomposites are shown in Figure 3. In the first step, all thermograms show weight loss of $\sim 10 \%$ from $20^{\circ}$ to $110^{\circ}$ $\mathrm{C}$, which is attributed to the vloss of constrained water contents inside the synthesized samples (Miahra et al., 2014). The bare PPy, in the second step, shows the weight loss of $30 \%$ occurred between $180^{\circ}$ to $300^{\circ} \mathrm{C}$ and is attributed to the removal of un-polymerized pyrrole or any solvent residue(Guo et al., 2009). While in the third step, the degradation of the PPy backbone starts due to the loss of its $\mathrm{C}, \mathrm{N}$, and $\mathrm{O}$ contents and caused the weight loss of $95 \%$ at $510{ }^{\circ} \mathrm{C}$ (Boukoussa et al., 2017). The $5 \%$ weight left at $1100{ }^{\circ} \mathrm{C}$ in the PPy sample is due to the carbon residue. The $\%$ weight 
loss by each sample is given in Table 2. TGA curve of Ag NPs shows its high thermal stability with the weight loss of only $30 \%$ at $110^{\circ} \mathrm{C}$. The $\mathrm{AgCl}$ : PPy nanocomposites show an obvious increase in their thermal stability in comparison to bare PPy owing to the high thermal stability property of the embedded AgCl phase (Ghadim et al., 2014). This is in trend with the Ag NPs fractions in the oxidation polymerization solution. This intercalation may lead to lower motility of polymeric chains when they are bonded by the $\mathrm{AgCl}$ moieties and the physiochemical interactions between these two phases as also inferred from FT-IR analysis (Guo et al., 2009). Hence, the more Ag NPs are added to the polymer, the more is the stability of the polymer backbone (Mishra et al., 2014).

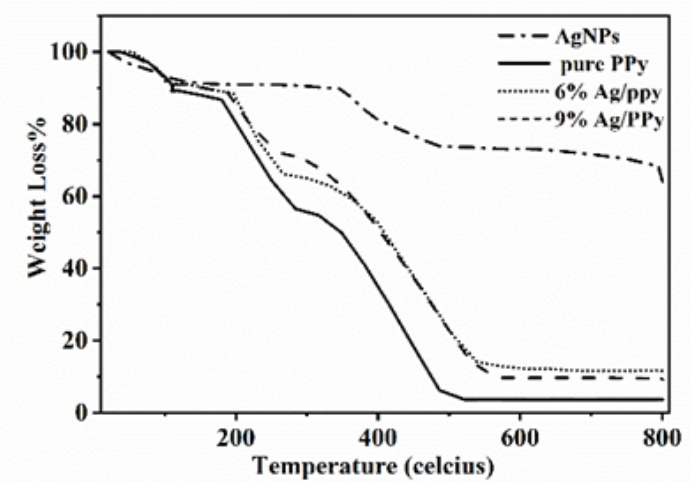

Fig. 3. TGA curves of $\mathrm{Ag} \mathrm{NPs}, \mathrm{AgCl}$ : PPy nanocomposites

Table 2. Weight loss data from TGA analysis of AgP NPs: PPy composite

\begin{tabular}{ccccc}
\hline Temperature & \multicolumn{4}{c}{ \% Weight loss } \\
\cline { 2 - 5 }$\left({ }^{\circ} \mathbf{C}\right)$ & Ag & Pure & $\mathbf{6 \%}$ & $\mathbf{9 \%}$ \\
& NPs & PPy & Ag/PPy & $\mathbf{A g / P P y}$ \\
\hline 100 & 7.7 & 10.7 & 8.5 & 9.1 \\
250 & 9.3 & 44.0 & 33.7 & 28.5 \\
450 & 26.9 & 95.1 & 83.6 & 86.5 \\
Residue & 33.2 & 96.1 & 88.2 & 90.3 \\
\hline
\end{tabular}

3.4 Field emission scanning electron microscopy (SEM)

SEM images of as-synthesized Ag NPs, PPy, and its composites are shown in Figure 4. Figure $4 \mathrm{a}$ shows the spherical and beanshaped morphology of synthesized Ag NPs of size ranging from 15 to $200 \mathrm{~nm}$. SEM image of the bare PPy exhibits the typical globular morphology with rough-surfaced hemispherical particles (150-300nm) engaged in clusters (Figure $4 \mathrm{~b}$ ). Figure $4 \mathrm{c}$ shows the SEM micrograph of $6 \%$ $\mathrm{AgCl}$ : PPy. This image reveals the globular evolution of morphology in the tree-like coral colonies. Each colony exhibits a high density of porosity and non-aggregated thin and fine tree branches of $\mathrm{AgCl}$ ranging from 30 to $50 \mathrm{~nm}$ as shown in the area squared in the red line in Figures $4 \mathrm{c}$ and $4 \mathrm{~d}$. These thin interconnected branches may provide the conductive pathways for the induced polarons that tend to increase their dc conductivity. Figure 4d shows the SEM micrograph of 9\% AgCl: PPy nanocomposite. That sample exhibits irregular-shaped morphology with randomly placed vertical sheets. The random symmetry of that composite is the major cause of loss of conjugation which may result in its decreased conductivity.

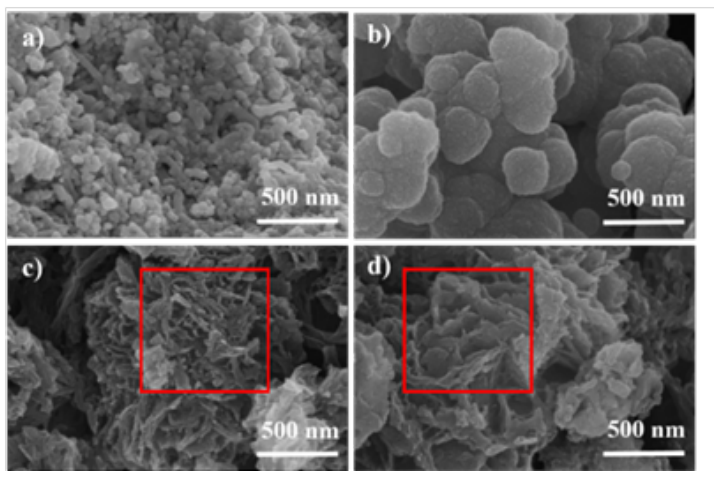

Fig. 4. SEM images of (a) Ag NPs, (b) bare PPy, (c) 6\% AgCl: PPy and (d) 9\% $\mathrm{AgCl}$ : PPy nanocomposites.

\subsection{UV-visible (UV-vis) absorbance spectroscopy}

The UV-Vis absorbance spectra of PPy show a distinct peak at $460 \mathrm{~nm}$ (Subramanian et al., 2015), which contributes to the pi-pi* transitions of $-\mathrm{C}=\mathrm{C}$ bond in the aromatic structure and polaronic transitions in PPy (Figure 5). The shift in this characteristic wavelength is observed for $\mathrm{AgCl}$ : $\mathrm{PPy}$ nanocomposites. The shift is not much prominent for other nanocomposites except for $6 \% \mathrm{AgCl}$ : PPy which has shifted from 
$455 \mathrm{~nm}$ to $470 \mathrm{~nm}$ which is characteristic of doped and highly conductive PPy (V.K. Gade et al., 2007). The observed shift is because of the interactions between $\mathrm{AgCl}$ and polymer (Shanthala et al., 2016). The onset wavelength seems to increase in parallel to the conductivity of the respective samples. It also represents the creation of several intermediate energy level bands between the conduction band and valance band in the synthesized nanocomposite. From the UV plot, the optical energy gap energy $(\mathrm{Eg})$ can be calculated for $\mathrm{AgCl}$ : PPy nanocomposites. The Kubelka-Munk ( $\mathrm{K}-\mathrm{M})$ method is used to get Tauc plot (Shanthala et al., 2016). The Eg is calculated using the following relation:

$$
\alpha h v=A[h v-E g]^{n}
$$

Where, $\mathrm{A}$ is the energy-independent constant, $\mathrm{n}$ is the nature of transition, its value can be $1 / 2$ or 2 following indirect or direct bandgap, respectively. Here in our case, we took it $1 / 2$. Figure 6 shows the Tauc plots and the band gaps of bare PPy and $\mathrm{AgCl}$ : PPy nanocomposites, calculated by the extrapolation of $(\alpha \mathrm{h} v)^{2}$ versus $\mathrm{h} v(\mathrm{eV})$. The Eg for PPy is found to be $1.79 \mathrm{eV}$ which is following the results obtained in the past. Tauc plots shown in Figure 4 presents the Eg of 1.80, 1.77, 1.67, and $1.73 \mathrm{eV}$ for PPy, $3 \%$ $\mathrm{AgCl}$ : PPy, 6\% AgCl: PPy, and 9\% AgCl: PPy, respectively. The results obtained from

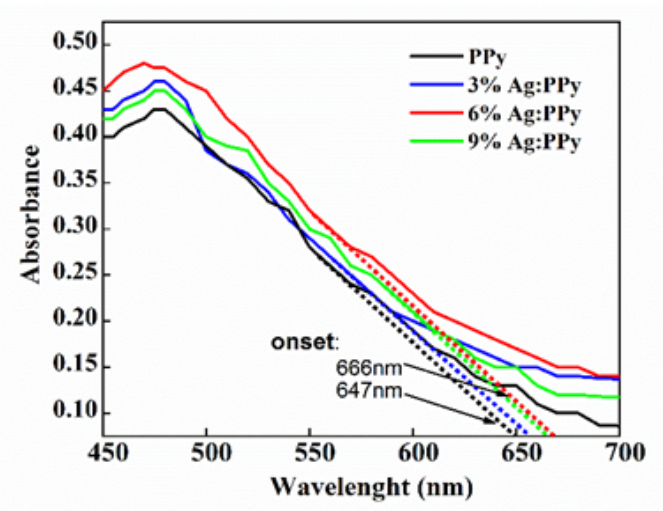

Fig. 5. UV-Vis absorbance of PPy and its composites

the plotted curves are all following the statement that high conductivity products gave high absorption values and lower bandgap energies. This leads to the fact that they need lower energy for the conduction of valance electron from HOMO to LUMO (Bredas et. al., 1984), hence imparting good conductive nature with increased absorption in the visible and near IR regions.

\subsection{Conductivity measurements}

Figure 7 depicts the characteristic currentvoltage (I-V) curves of PPy and its composites. The I-V behavior of each composite shows linear variation with the amount of loaded Ag NPs in the polymerization mixture, which depicts their good ohmic behavior. It can be attributed to the mobility of ions in polymer chains, induced crystallinity in polymer due to added crystalline inorganic phase, and the physiochemical interactions between the polymer and $\mathrm{AgCl}$ moities (Ramesan et al., 2018). Figure 8 shows the room temperature DC conductivities of PPy and $\mathrm{AgCl}$ : PPy composites. The conductivity of PPy was found to be only $1.39 \mathrm{~S} \mathrm{~cm}^{-1}$, while the electrical conductivity is increased to 3.25 $\mathrm{S} \mathrm{cm}-1$ for 3\% Ag: PPy (Table 3). A sharp increase in the conductivity is observed for 6\% AgCl: PPy $\left(1355 \mathrm{~S} \mathrm{~cm}^{-1}\right)$. It illustrates the more compendious and better conjugated symmetrical arrangement of intercalated $\mathrm{AgCl}$ in the PPy backbone.

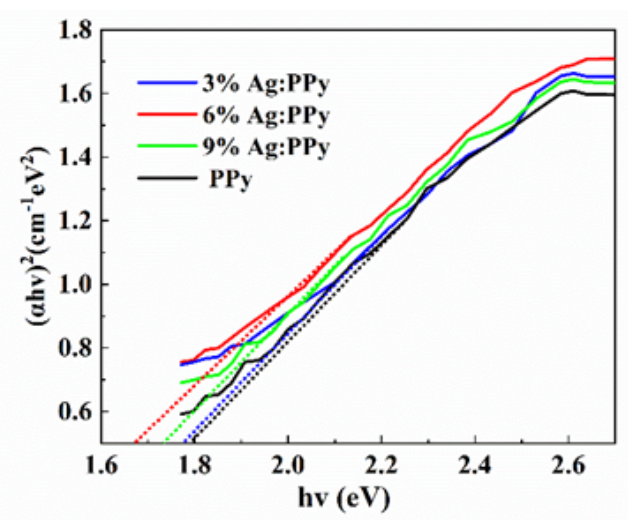

Fig. 6. Tauc plots of PPy and its composites

This is also inferred from the FT-IR analysis that depicts the shifting of peaks towards lower wavenumbers on composite formation, 


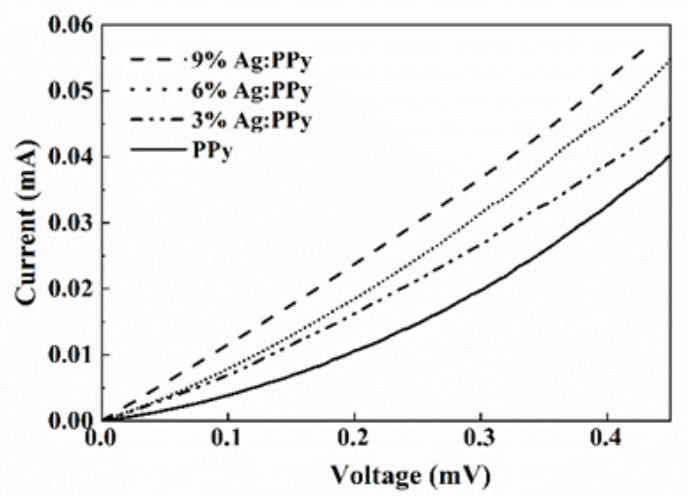

Fig. 7. I-V characteristic plots of PPy and $\mathrm{AgCl}$ : PPy nanocomposites

Table 3. Variation of DC conductivity with the wt.\% of Ag NPs in polymerization mixture.

\begin{tabular}{lll}
\hline $\begin{array}{l}\text { Sample } \\
\text { specification }\end{array}$ & $\begin{array}{l}\text { Ag NPs } \\
\text { contents (g) }\end{array}$ & $\begin{array}{l}\text { Conductivity } \\
\left(\mathbf{S ~ c m}^{-1}\right)\end{array}$ \\
\hline Pure PPy & 0.0 & 1.39 \\
3\% Ag:PPy & 0.067 & 3.25 \\
6\% Ag:PPy & 0.134 & 1355 \\
9\% Ag:PPy & 0.201 & 30.91 \\
\hline
\end{tabular}

which lead to more ordered polymeric structure to support the conductivity(Jamail et al., 2013) The conductivity dramatically decreased by $6 \% \mathrm{AgCl}$ : PPy $\left(30.91 \mathrm{~S} \mathrm{~cm}^{-1}\right)$ loading which may be due to the aggregation of the $\mathrm{AgCl}$ structures, leading to vague interaction between the NPs and polymer (Ramesan et al., 2018).

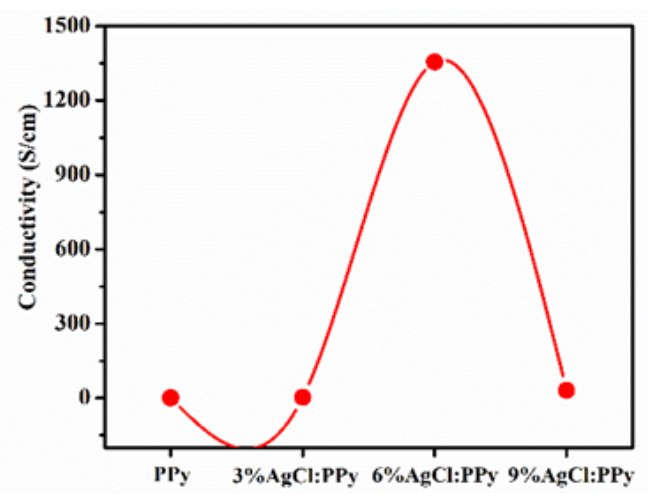

Fig. 8. DC conductivities at room temperature with varied wt. \% of Ag NPs in PPy

\section{Conclusion}

In summary, we have developed a facile method to synthesize $\mathrm{AgCl}$ : PPy nanocomposites with unique tree-like coral morphology. The developed nanocomposites exhibit distinct physical characteristics. The XRD analysis confirms the formation $\mathrm{AgCl}$ : PPy nanocomposites with increased crystallinity and reduced particle size of $4 \mathrm{~nm}$ in comparison to synthesized silver nanoparticles $(\sim 10 \mathrm{~nm})$. The thermal stability of the host polymer increased after the incorporation of $\mathrm{AgCl}$ owing to developed physiochemical interactions between $\mathrm{AgCl}$ and PPy, as evidenced from FTIR results. The increased absorption in the UV region (647 to $666 \mathrm{~nm}$ ) leading to the highest conductivity at the critical weight percentage of $\mathrm{Ag}$ NPs in $\mathrm{AgCl}$ : PPy nanocomposites. Thus, our synthesized $\mathrm{AgCl}$ : PPy nanocomposites with thin interconnected branches like morphology; reduced bandgap from 1.8 to $1.67 \mathrm{eV}$, and improved crystallinity in comparison to bare PPy can be used in photocatalytic and sensor applications.

\section{ACKNOWLEDGEMENTS}

This research work is supported by the Higher Education Commission (HEC), Islamabad, School of Physical Sciences, and the Institute of Chemistry, University of the Punjab, Pakistan.

\section{References}

Ahmed, K., Kanwal, F., Ramay, S. M., Atiq, S., Rehman, R., Ali, S. M., \& Alzayed, N. S. (2018). Synthesis and characterization of $\mathrm{BaTiO} /$ polypyrrole composites with exceptional dielectric behavior. Polymers, 10(11), 1273.

Blinova, N. V., Stejskal, J., Trchová, M., Prokeš, J., \& Omastová, M. (2007). Polyaniline and polypyrrole: A comparative study of the preparation. European polymer journal, 43(6), 2331-2341.

Bolto, B. A., McNeill, R., \& Weiss, D. E. (1963). Electronic conduction in polymers. 
III. Electronic properties of polypyrrole. Australian Journal of Chemistry, 16(6), 1090-1103.

Boukoussa, B., Abidallah, F., Abid, Z., Talha, Z., Taybi, N., El Hadj, H. S., ... \& Bengueddach, A. (2017). Synthesis of polypyrrole/Fe-kanemite nanocomposite through in situ polymerization: effect of iron exchange, acid treatment, and $\mathrm{CO} 2$ adsorption properties. Journal of materials science, 52(5), 2460-2472.

Brédas, J. L., Thémans, B., Fripiat, J. G., André, J. M., \& Chance, R. R. (1984). Highly conducting polyparaphenylene, polypyrrole, and polythiophene chains: An $a b$ initio study of the geometry and electronic-structure modifications upon doping. Physical Review B, 29(12), 6761.

Cheah, K., Forsyth, M., \& Truong, V. T. (1999). An XRD/XPS approach to structural change in conducting PPy. Synthetic metals, 101(1-3), 19.

Chen, W., Li, X., Xue, G., Wang, Z., \& Zou, W. (2003). Magnetic and conducting particles: preparation of polypyrrole layer on $\mathrm{Fe} 3 \mathrm{O} 4$ nanospheres. Applied surface science, 218(1-4), 216-222.

Chougule, M. A., Pawar, S. G., Godse, P. R., Mulik, R. N., Sen, S., \& Patil, V. B. (2011). Soft Nanoscience Letters 1, 6-10.

Du, C., Wang, A., Fei, J., Zhao, J., \& Li, J. (2015). Polypyrrole-stabilized gold nanorods with enhanced photothermal effect towards two-photon photothermal therapy. Journal of Materials Chemistry B, 3(22), 4539-4545.

Gade, V. K., Shirle, D. J., Gaiwad, P. D., Kakde, K. P., Savale, P. A., Kharat, H. J., Shirsat, M. P. (2007). Synthesis and characterization of Ppy-PVS, Ppy-PTS, and Ppy-DBS composite films. International Journal of polymeric materials and polymeric biomaterials, 56(107), 107-114.

Ghadim, M. F., Imani, A., \& Farzi, G. (2014). Synthesis of PPy-silver nanocomposites via in situ oxidative polymerization. Journal of Nanostructure in Chemistry, 4(2), 101.mk

Gu, S., Li, B., Zhao, C., Xu, Y., Qian, X., \& Chen, G. (2011). Preparation and characterization of visible-light-driven $\mathrm{AgCl} / \mathrm{PPy}$ photocatalyst. Journal of Alloys and Compounds, 509(18), 5677-5682.

Guo, Z., Shin, K., Karki, A. B., Young, D. P., Kaner, R. B., \& Hahn, H. T. (2009). Fabrication and characterization of iron oxide nanoparticles filled polypyrrole nanocomposites. Journal of Nanoparticle Research, 11(6), 1441-1452.

Hayashi, S., Togawa, Y., Yamamoto, S. I., Koizumi, T., Nishi, K., \& Asano, A. (2017). Synthesis of $\pi$-conjugated network polymers based on fluoroarene and fluorescent units via direct arylation polycondensation and their porosity and fluorescent properties. Journal of Polymer Science Part A: Polymer Chemistry, 55(23), 3862-3867.

Jamail, M. A. M. Piah, N. A. Muhamad, R. A. Zainir, N. F. Kasri, Kamarudin, Q. (2013). International Journal on Electrical Engineering and Informatics, 5, 217-225.

Kanazawa, K. K., Diaz, A. F., Geiss, R. H., Gill, W. D., Kwak, J. F., Logan, J. A., ... \& Street, G. B. (1979). 'Organic metals': polypyrrole, a stable synthetic 'metallic polymer. Journal of the Chemical Society, Chemical Communications, 1(19), 854-855.

Kanwal, F., Siddiqi, S. A., Batool, A., Imran, M., Mushtaq, W., \& Jamil, T. (2011). Synthesis of polypyrrole-ferric oxide (PPy-Fe2O3) composites and study of their structural and conducting properties. Synthetic Metals, 161(3-4), 335-339. 
Kim, W. H., \& AJ, M. kinen, N. Nikolov, R. Shashidhar, H. Kim, ZH Kafafi. (2002). Appl. Phys. Lett, 80, 3844. Kurt, A., \& Yilmaz, P. (2016). Thermal decomposition kinetics of benzofuran derived polymer/ organosilicate nanocomposites. Kuwait Journal of Science, 43(2). 172-184

Levi, M. D., Gofer, Y., \& Aurbach, D. (2002). A synopsis of recent attempts toward the construction of rechargeable batteries utilizing conducting polymer cathodes and anodes. Polymers for advanced technologies, 13(10-12), 697-713.

Liu, J., Wang, J., Yu, X., Li, L., \& Shang, S. (2015). One-pot synthesis of polypyrrole/ $\mathrm{AgCl}$ composite nanotubes and their antibacterial properties. Micro \& Nano Letters, 10(1), 50-53.

Mishra, A. K. (2014). Nanocomposites in wastewater treatment. Jenny Stanford Publishing. pp. 221-247.

Mishra, S., Singh, B. R., Singh, A., Keswani, C., Naqvi, A. H., \& Singh, H. B. (2014). Biofabricated silver nanoparticles act as a strong fungicide against Bipolaris sorokiniana causing spot blotch disease in wheat. PLoS One, 9(5).

Novák, P. (1992). Limitations of polypyrrole synthesis in water and their causes. Electrochimica Acta, 37(7), 1227-1230.

Pang, X. Y., MING-WEI, D. U. A. N., ZHI-XIAO, Z. H. A. I., \& Yu, T. (2015). An intumescent flame retardant-expandable graphite: Preparation, characteristics and flame retardance for polyethylene. Kuwait Journal of Science, 42(1). 133-149

Partch, R., Gangolli, S. G., Matijević, E., Cal, W., \& Arajs, S. (1991). Conducting polymer composites: I. Surface-induced polymerization of pyrrole on iron (III) and cerium (IV) oxide particles. Journal of colloid and interface science, 144(1), 27-35.
Pitchai, S., Jeyakodi, M. J., Swarna, N. (2014). Study on polyester fabric using polyvinyl alcohol in alkaline medium to enhance the hydrophilic character. Kuwait Journal of Science, 41(3), 177-190.

Ramesan, M. T., \& Santhi, V. (2018). Synthesis, characterization, conductivity, and sensor application study of polypyrrole/ silver doped nickel oxide nanocomposites. Composite Interfaces, 25(8), 725-741.

Ravichandran, S. Sundarrajan, J. Venugopal, S. Mukherjee, Ramakrishna, S. (2010). Journal of the Royal Society, Interface / the Royal Society, 7(5), S559579.

Ruggeri, G., Bianchi, M., Puncioni, G., \& Ciardelli, F. (1997). Molecular control of electric conductivity and structural properties of polymers of pyrrole derivatives. Pure and applied chemistry, 69(1), 143-150.

Šetka, M., Drbohlavová, J., \& Hubálek, J. (2017). Nanostructured polypyrrole-based ammonia and volatile organic compound sensors. Sensors, 17(3), 562.

Shanthala, V. S., Devi, S. S., \& Murugendrappa, M. V. (2016). Optical band gap Studies of Polypyrrole doped with $\mathrm{CuZnFe} 2 \mathrm{O} 4$ nanoparticles. International Journal of Scientific and Research Publications, 6(9), 21-26.

Shanthala, V. S., Shobha Devi, S. N., \& Murugendrappa, M. V. (2017). Synthesis, characterization, and DC conductivity studies of polypyrrole/copper zinc iron oxide nanocomposites. Journal of Asian Ceramic Societies, 5(3), 227-234.

Stenger-Smith, J. D. (1998). Intrinsically electrically conducting polymers. Synthesis, characterization, and their applications. Progress in Polymer Science, 23(1), 57-79. 
Subramanian, J. Chandrasekaran, D. M.

D, R. (2015). Magesh, in Journal of Polymer Engineering, 37, 5.

Vernitskaya, T. V., \& Efimov, O. N. (1997). Polypyrrole: A conducting polymer (synthesis, properties, and applications). Успехи химии, 66(5), 502-505.

Wang, W., Li, W., Zhang, R., \& Wang, J. (2010). Synthesis and characterization of Ag@ PPy yolk-shell nanocomposite. Synthetic metals, 160(21-22), 2255-2259.

Yang, X., Li, L., \& Zhao, Y. (2010). Ag/ $\mathrm{AgCl}$-decorated polypyrrole nanotubes and their sensory properties. Synthetic metals, 160(17-18), 1822-1825.

Yi, N., \& Abidian, M. R. (2016). Conducting polymers and their biomedical applications. In Biosynthetic Polymers for Medical Applications (pp.243-276). Woodhead Publishing.

Younas, T., Ali, I., \& Jamil, N. (2015). Polyhydroxyalkanotes (PHAs) production by using canola oil as a carbon source from bacteria isolated near paper pulp industry. Kuwait Journal of Science, 42(2). 236-249.

Yusoff, N. (2019). Graphene-Polymer Modified Electrochemical Sensors. In Graphene-Based Electrochemical Sensors for Biomolecules (pp. 155-186). Elsevier.

$\begin{array}{lr}\text { Submitted: } & 17 / 05 / 2020 \\ \text { Revised: } & 22 / 10 / 2020 \\ \text { Accepted: } & 22 / 10 / 2020 \\ \text { DOI: } & 10.48129 / \text { kjs.v48i4.9757 }\end{array}$

